\title{
SAND TRANSPORT IN THE SWASH ZONE IN LOW-ENERGY WAVE CONDITIONS
}

\author{
Paulo A. Silva ${ }^{1}$, Tiago Abreu², Francisco Sancho ${ }^{3}$, Óscar Ferreira ${ }^{4}$, Maria Bezerra ${ }^{4}$, Luís \\ Ferreira $^{5}$, Mariana Rocha ${ }^{1}$ and Conceição J. Fortes ${ }^{3}$
}

\begin{abstract}
The interaction between waves and morphological changes at the beach face under low wave-energy conditions is examined from data obtained during a field survey at Praia de Faro (Algarve, Portugal). This work describes and analyses measurements of swash velocities acquired with current-meters, water surface elevation obtained with pressure transducers and topographic surveys undertaken during the field campaign. Estimations of sand transport rates are calculated considering different empirical formulations, and the results are then compared against the transport rates deduced from topographic measurements. A representative swash velocity time series based on the non-linear formulation of Abreu et al. (2010) is derived to study the dependence of the bed shear-stress skewness on the tidal phase and how this can affect sediment transport in the swash zone.
\end{abstract}

Keywords: field measurements; swash; sediment transport; Praia de Faro

\section{INTRODUCTION}

The swash zone is characterized by an intermittent water motion that covers and uncovers the sand bed. The flow process can be divided in two distinct phases: the uprush, mostly determined by the incident wave and breaking conditions and the backwash, driven by gravity. Sediment transport in this zone is important to shoreline evolution as all the sediment moving onshore to the beach is carried across it (Nielsen, 2009). The flow and sediment transport in the swash zone are complex and the details are unknown. Different processes act simultaneously, contributing to sediment transport in the swash zone: (i) the interaction between the moving water and the soil in terms of in/exfiltration processes (e.g., Nielsen, 2009); (ii) the nonlinearities of the flow (velocity and acceleration skewness); (iii) the breaking-wave generated turbulence and its advection to the swash zone (e.g., Hsu and Raubenheimer, 2006).

Important advances have been made in modeling sediment transport in the swash zone (for a review, see the work of Bakhtyara et al., 2009). Energetics-based models, such as the Bailard (1981) formulation, consider sediment transport as a function of higher-order velocity moments (velocity skewness and velocity kurtosis) and are able to predict nearshore bar formation and offshore bar migration, under energetic wave conditions. Given the relative success of that formulation in the nearshore, it was applied to the swash zone, in an attempt to predict shoreline erosion and/or accretion (e.g., Masselink and Russel, 2006; Masselink et al., 2008; Emmanuel et al., 2009). However, as shown by Masselink and Russel (2006), the energetics approach fails to predict the observed onshore sediment transport in the swash zone.

A common finding is that the friction coefficient differs between uprush and backwash, with Masselink and Hughes (1998), Cox et al. (2000) and Conley and Griffin (2004), for example, presenting time-averaged uprush coefficients typically larger than the time-averaged backwash coefficients. Barnes et al. (2009) addresses these issues by providing the first comprehensive data set of direct stress measurements obtained using a shear plate within the swash zone. Results show a rapid temporal variation of the bed shear stress across the leading edge of the uprush, which is typically two to four times greater than the backwash shear stress at the corresponding flow velocity. However, based on high-resolution velocity data, Puleo et al. (2012) found that there is little difference in the friction coefficient between the two phases of motion.

A Meyer-Peter and Müller (1948) bed-load type formulation was also applied to predict the net transport rates in the swash zone (e.g., Masselink et al., 2005). Nielsen (2002) extended the bed shear stress to take into account the acceleration effects and Austin et al. (2009) the in/exfiltration processes.

First, this paper presents the results gathered from a field survey carried out at Praia de Faro and characterizes the flow in the swash zone, for example, in terms of the number of swash events, the

\footnotetext{
${ }^{1}$, Physics Department \& CESAM, University of Aveiro, Campus de Santiago, 3810-193 Aveiro, Portugal

${ }^{2}$ Civil Engineering Department \& CESAM, Polytechnic Institute of Viseu, ESTGV Campus de Repeses, 3504-510 Viseu, Portugal

${ }^{3}$ Hydraulics and Environment Department, National Laboratory for Civil Engineering, Av. do Brasil, 101, 1700-066

Lisboa, Portugal

${ }^{4}$ CIMA, University of Algarve, Edifício 7, Campus de Gambelas, 8005-139 Faro, Portugal

${ }^{5}$ EADS Astrium GmbH, AED51 - Optical Instruments, Robert-Kochstr. 1, 82024 Taufkirchen, Germany
} 
maximum orbital velocities during uprush and downwash and its dependence on the tidal phase. Then, estimations of sand transport rates are calculated with the formulations describe above, being the results compared with transport rates deduced from the topographic measurements performed. And finally, a representative swash velocity time series based on the formulation of Abreu et al. (2010) is derived to study the influence of bed shear stress skewness on the tidal phase and how this affects sediment transport in the swash zone.

\section{STUDY AREA AND FIELD MEASUREMENTS}

An intensive campaign was held at Praia de Faro, southern Portugal, during four days, from the $25^{\text {th }}$ to the $28^{\text {th }}$ of March, 2009. Praia de Faro is located in the barrier island of Ancão Peninsula, in the western border of the Ria Formosa lagoon (Figure 1). The mean tidal range at this site is $2.8 \mathrm{~m}$, during spring tides, and $1.3 \mathrm{~m}$ during neap tides, with a maximum tidal range of $3.5 \mathrm{~m}$ (Instituto Hidrográfico, 1998). The offshore wave climate is dominated by W-SW waves (71\% of occurrences) (Costa et al., 2001), although southeast short-period waves generated by regional winds are also frequent (about 23\%) (Costa et al., 2001). Wave energy is moderate, with a significant annual average offshore height of $1.0 \mathrm{~m}$ and an average peak period of $8.2 \mathrm{~s}$; a significant wave height lower than $1 \mathrm{~m}$ is registered during $68 \%$ of the year (Costa et al. 2001).

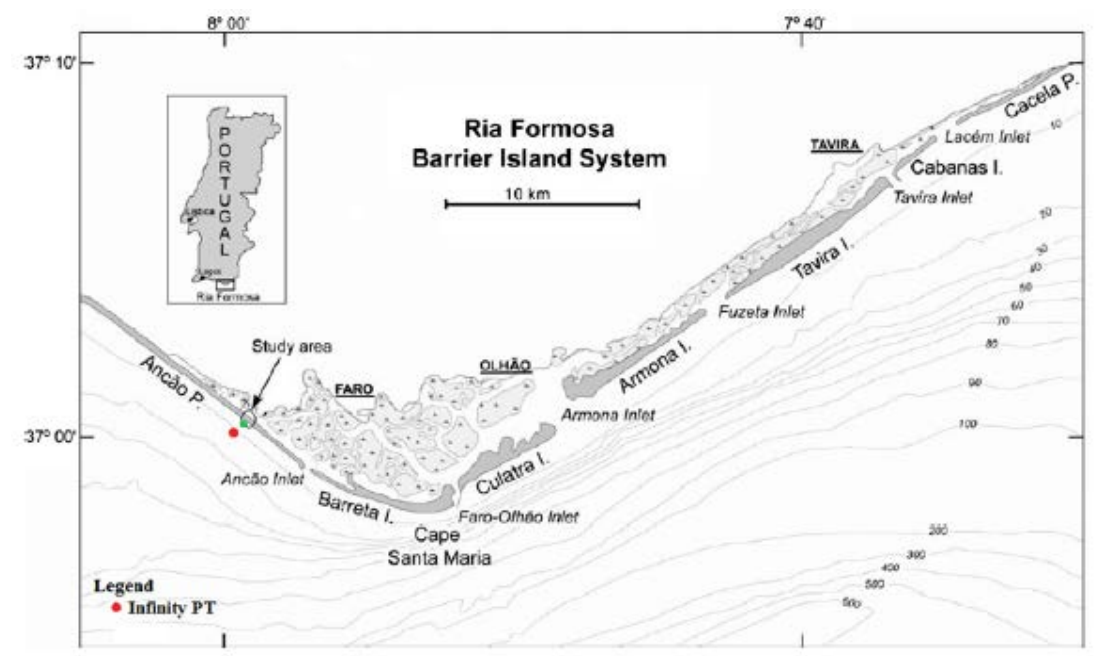

Figure 1. Location of the study area (base map adapted from Matias et al., 2009)

During the field campaign an array of measurement devices was deployed, both in the nearshore and in the beach face, to measure waves, velocities and to carry out topo-bathymetric surveys along two cross-shore transects. A complete description of the experiment and instruments is given in Vousdoukas and Almeida (2009) and Fortes et al. (2012). For the purpose of this work, only measurements of the sea-surface elevation performed with a LevelTroll pressure transducer (PT3) and velocities measured with an Acoustic Doppler Velocimeter (ADV) SONTEK $10 \mathrm{MHz}$ at the swash zone are analyzed. These instruments were fixed to a structure, $1.56 \mathrm{~m}$ above the MSL as depicted in Figure 2. The distance between the ADV sampling volume and the pressure transducer probe to the sandy bottom was about $\sim 7 \mathrm{~cm}$. This ensured that the ADV control volume was neither within the sand bed nor in high sediment-concentration zones, hence avoiding malfunctions. The PT3 and ADV sampling rates were 5 and $20 \mathrm{~Hz}$, respectively. Furthermore, in order to monitor the morphological changes, topographic surveys of the study area were carried out at each low tide, using an RTK GPS. The nearshore incident-wave data measured by an Infinity PT (Pressure Transducer), placed at $11 \mathrm{~m}$ below the mean sea level (MSL), and by another pressure transducer (PT2), placed at $0.2 \mathrm{~m}$ above the MSL, are also presented to define the wave conditions during the field campaign.

During the campaign, 5 time series were collected with the ADV and PT3, corresponding to 5 consecutive high tides. Only the data corresponding to the second high tide ( $27^{\text {th }}$ of March between $0 \mathrm{~h}$ and $5 \mathrm{~h}$ ) is going to be presented here due to a malfunction of either the ADV or PT3 during the other high tides. 


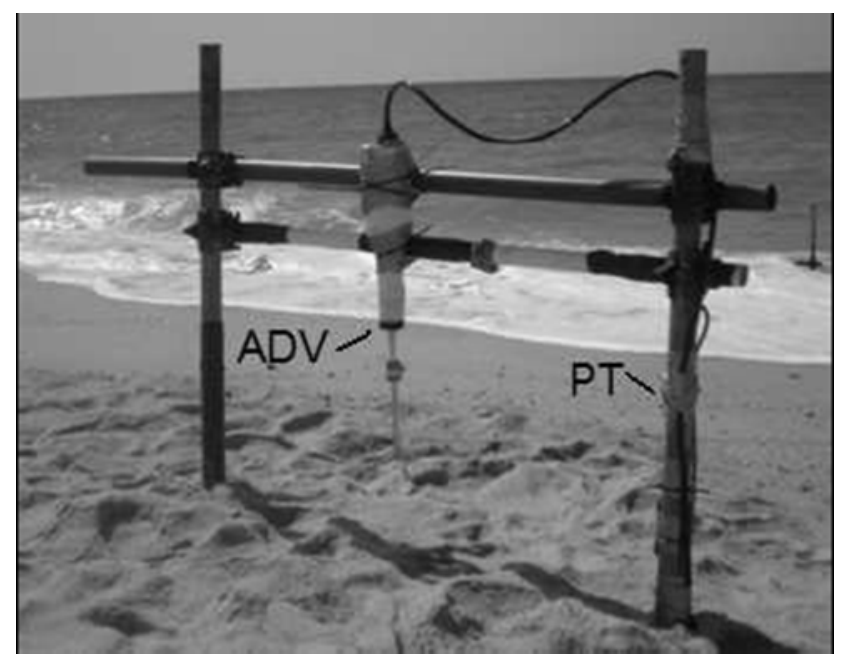

Figure 2. ADV and PT deployment structure during the field campaign.

\section{RESULTS}

\section{Incident Waves}

The significant wave height $\left(\mathrm{H}_{\mathrm{S}}\right)$ computed from the free-surface elevation data obtained offshore (Infinity) and in the shoreface (PT2) is presented in Figure 3. The offshore $\mathrm{H}_{\mathrm{S}}$ values ranged between 0.2 and $0.6 \mathrm{~m}$, arriving from SE (until the $28^{\text {th }}$ March) and from SW (during $28^{\text {th }}$ March); the mean wave period (not shown) was of about $6 \mathrm{~s}$ for most of the acquisition time, with an exception for the SW wave conditions, during which larger values were observed. The $\mathrm{H}_{\mathrm{S}}$ values measured in the shoreface were slightly higher than the offshore values but showed the same trends in time. The incident wave conditions at the beach during the field campaign corresponded to low-energy wave conditions.

\section{Topographic surveys}

Figure 4 shows the bottom elevation profiles measured along the transect where the ADV and the PT3 were placed. The six lines plotted refer to the measurements obtained at each low tide. The distances along the profile refer to the location in the upper beach where topographic variations were minor. Based on this data, the volumetric changes inland of the ADV position $(X=14 \mathrm{~m})$ were computed during each tide and are presented in Table 1. The beach slope in the intertidal zone was 0.1.

Erosion conditions were detected during the first 3 tides and accretion during the last two. Major changes were observed during $\mathrm{T} 5$, between the $5^{\text {th }}$ and $6^{\text {th }}$ surveys, when the incident wave height increased (Figure 3a). The differences between the bed-elevation measurements add only to a few $\mathrm{cm}$, in some cases within the resolution of the DGPS system. During T2, between the $2^{\text {nd }}$ and $3^{\text {rd }}$ surveys, the bed level between $\mathrm{X}=0$ and $\mathrm{X}=14 \mathrm{~m}$ changed, on average, approximately $0.01 \mathrm{~m}$.

PT3

Figure 5 presents the raw pressure data recorded by the pressure transducer. The sensor collected data during approximately $4 \mathrm{~h}$ between $00 \mathrm{~h} 30 \mathrm{~m}$ and $04 \mathrm{~h} 30 \mathrm{~m}$, on the $27^{\text {th }}$ of March. Each swash event is identified when the pressure differs from the atmospheric pressure and is quantified in terms of its duration (T) and height (H). A total number of 1135 swash events was identified in the whole record. The number of swash events, the percentage of inundation and the average values of the significant swash height $\mathrm{H}_{\mathrm{s}}$ and $\mathrm{T}$ were computed for 10-minute intervals along the recorded data and are plotted in Figure 6, as a function of time. The high tide occurred at 02h30min. As the percentage of inundation is below $100 \%$, it means that the sensor was in the swash zone. 


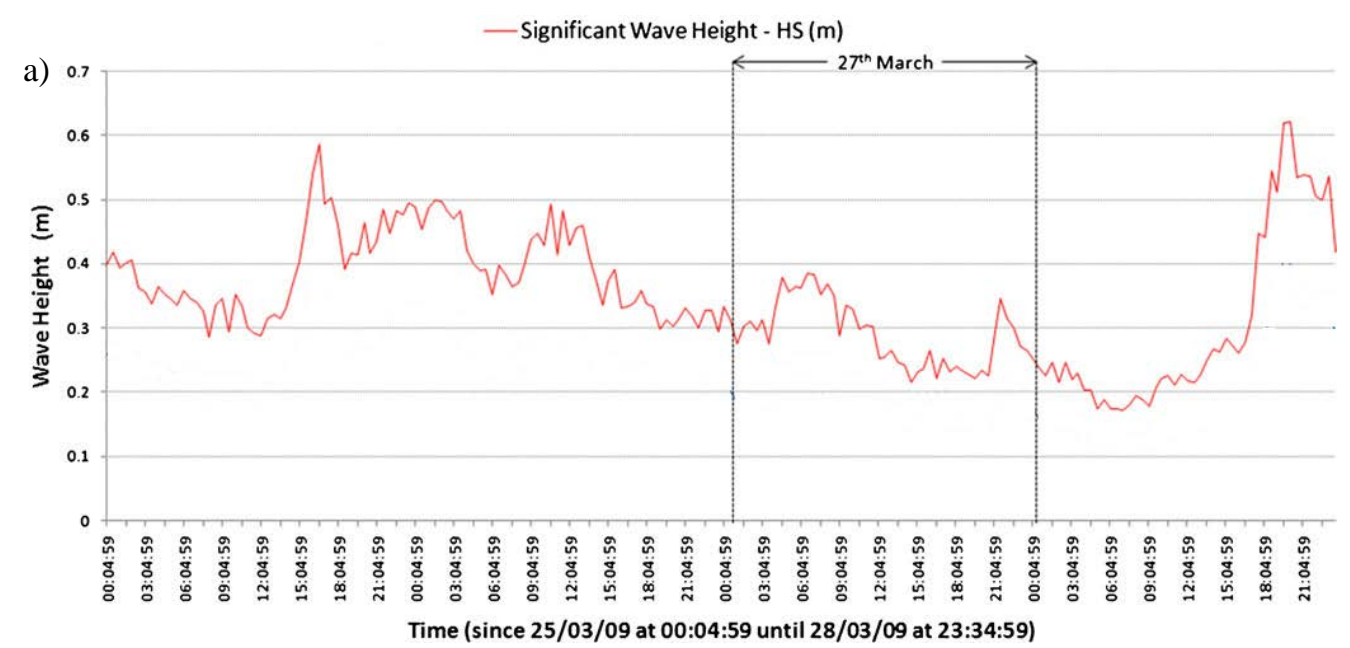

b)

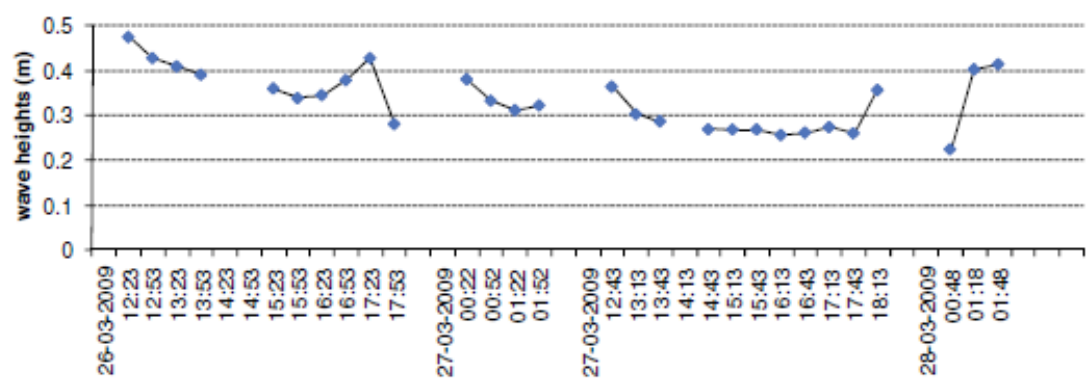

Figure 3. Significant wave height data, HS (m) (a) Infinity PT; (b) PT2 (adapted from Fortes et al., 2012)

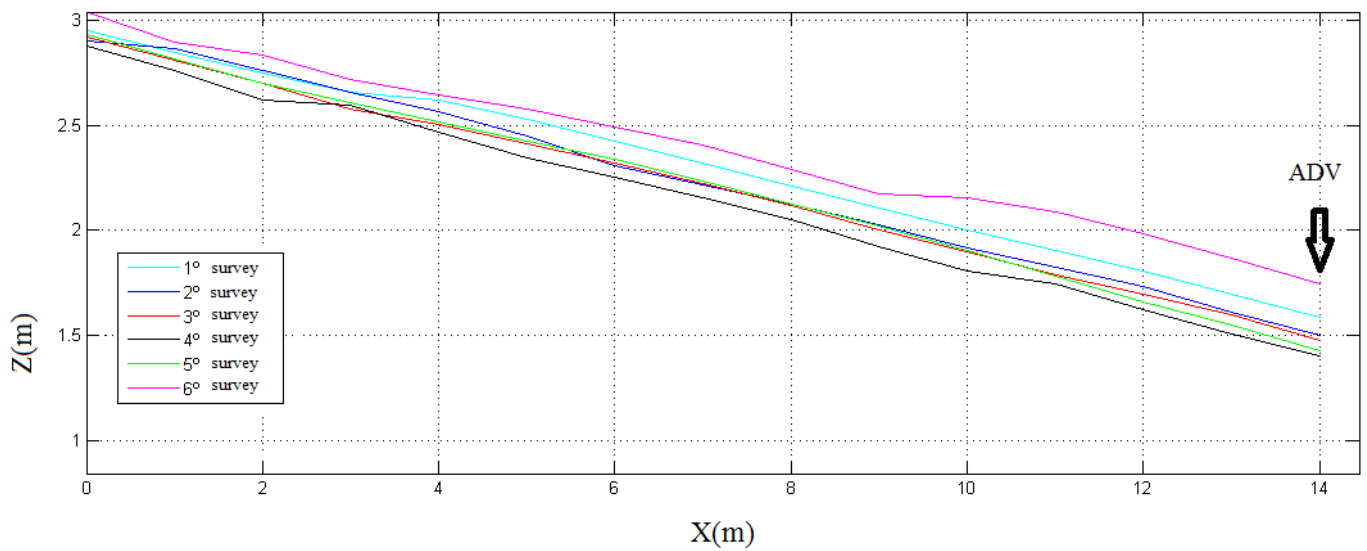

Figure 4. Topographic surveys carried out at low tide: 1 survey: 26.03 .09 - 08h11m; 2 survey: 26.03 .09 20h:23m; 3 survey: 27.03.09 - 08h:43m; 4 survey: $27.03 .09-20 \mathrm{~h}: 57 \mathrm{~m} ; 5$ survey: $28.03 .09-09 \mathrm{~h}: 16 \mathrm{~m} ; 6$ survey: 28.03.09-21h:33m.

\begin{tabular}{|c|c|c|c|c|}
\hline \multicolumn{5}{|c|}{ Table 1. Volumetric bed changes $\left(\mathbf{m}^{3} / \mathbf{m}\right)$} \\
\hline T1 & T2 & T3 & T4 & T5 \\
\hline-0.29 & -0.15 & -0.03 & 0.34 & 0.99 \\
\hline
\end{tabular}




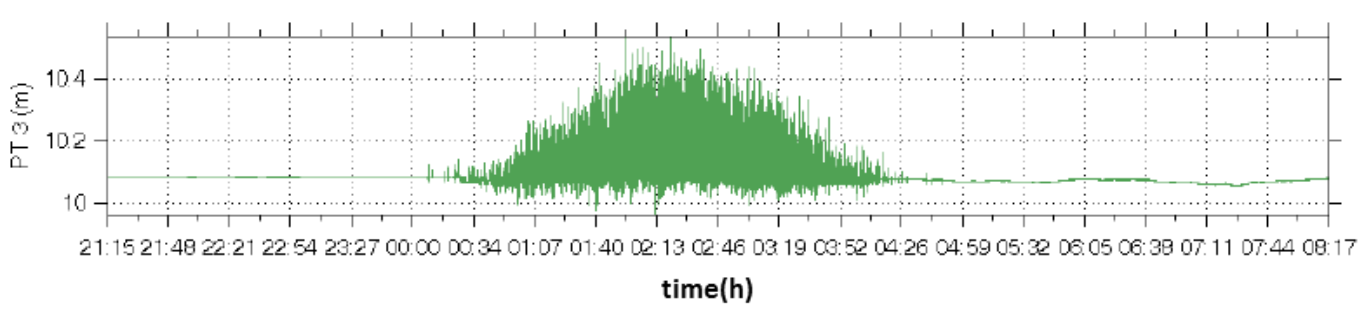

Figure 5. PT3 Time series of pressure measured by the PT3 during the $2^{\text {nd }}$ tide.
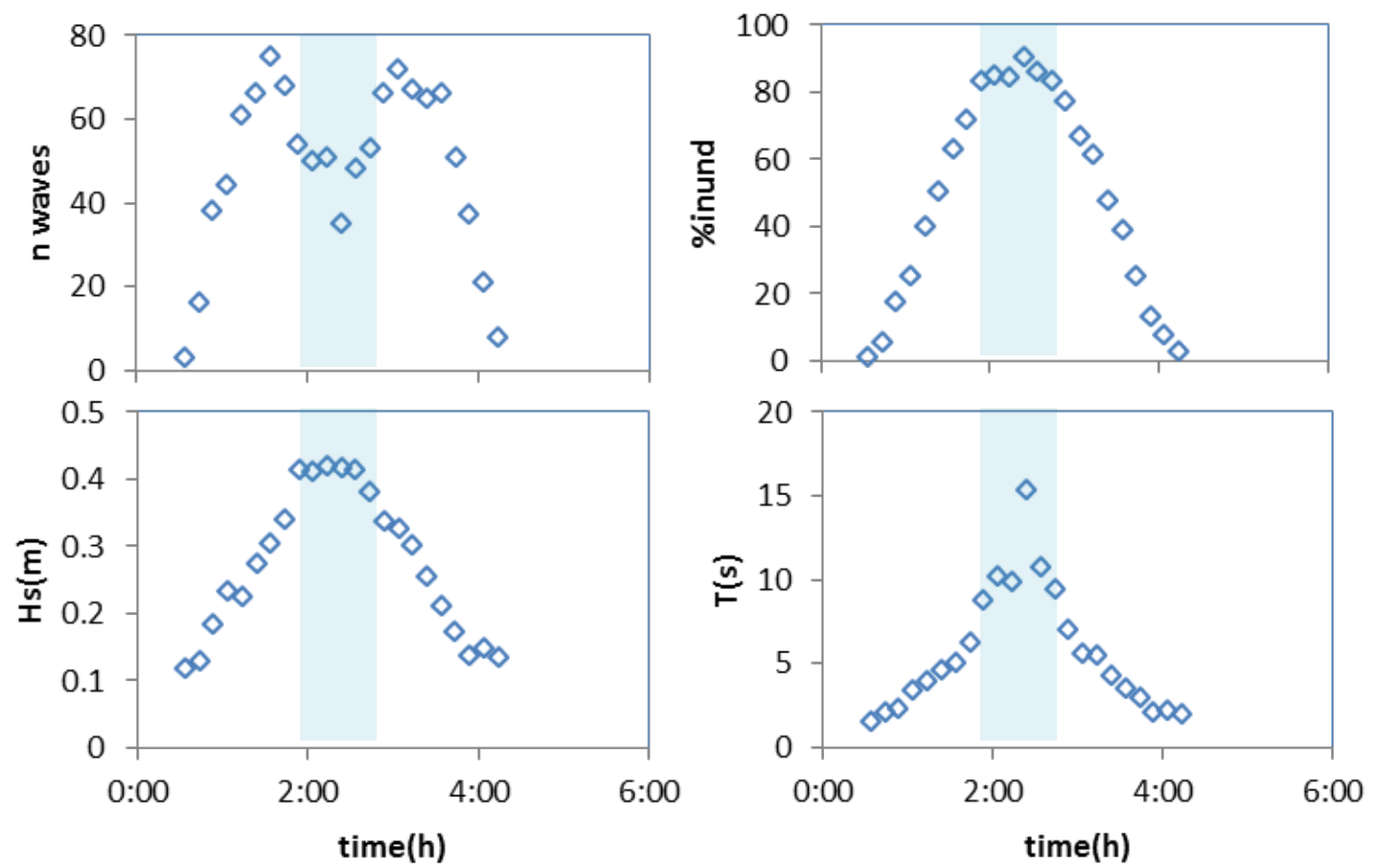

Figure 6. РT3 data: number of swash events, percentage of inundation, Hs and T at 10 min intervals: 2 tide. The shaded rectangle represents the transition between swash and surf zones.

In general, the number of swash events increased with rising tide but decreased around high tide when several consecutive swash events were considered a "single event" (note the corresponding increase in T). This has been identified as a transition zone between the swash and surf zones, and for reference, it is shaded in Figure 6 and the following ones. The significant swash height increases until $0.4 \mathrm{~m}$. The swash motion occurs at short-wave frequencies with period between 6 and $8 \mathrm{~s}$ (not shown), typical of steep beaches.

\section{ADV}

The ADV recorded the 3 components of instantaneous velocity during the $2^{\text {nd }}$ tide. In this paper, only the cross-shore velocity component $\left(U_{x}\right)$ is presented and analyzed. As an example, Figure 7 shows the records of $U_{x}$ during $100 \mathrm{~s}$ : the black continuous line represents the raw data and the red dots the withdrawn data after a filter was applied. ADV data were considered consistent when the signal correlation was $>70 \%$, the signal-noise ratio $>40$ and the time duration of each swash event $>1 \mathrm{~s}$. By applying these criteria, 462 swash events were identified, which is a lower number than those identified by the PT during the same time interval. Although the ADV control volume was placed at the same height above the bed as the PT3 $(\sim 7 \mathrm{~cm})$, the transmitters of the ADV were located $\sim 11 \mathrm{~cm}$ above that level. These must be fully immersed for data acquisition, which justifies why not all the swash events were recorded by the ADV, especially at the beginning and end of the tide. 


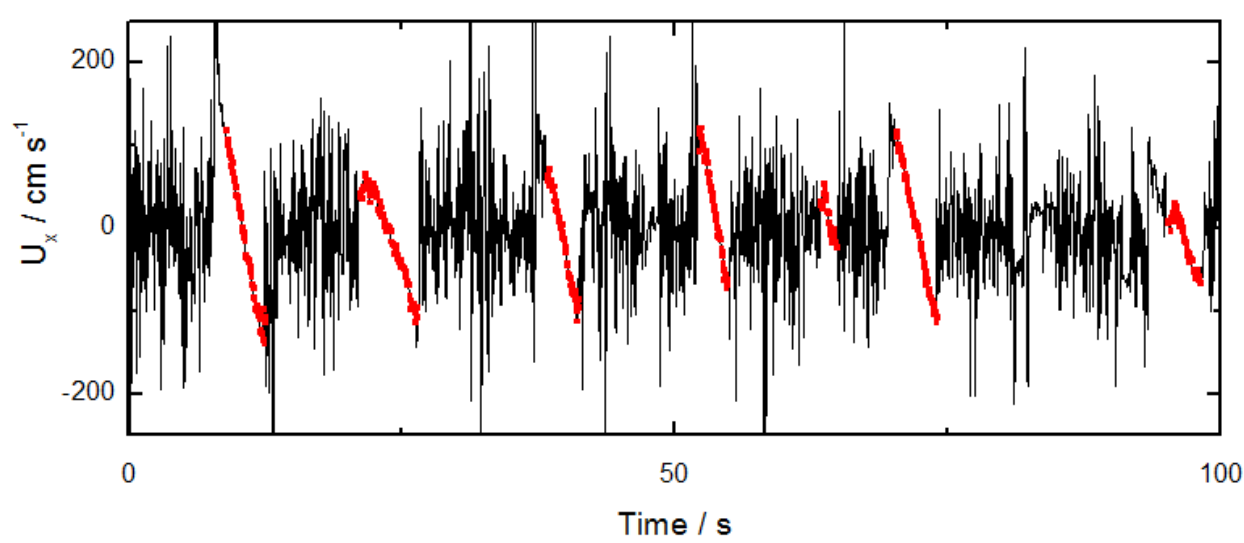

Figure 7. Example time series of cross-shore velocity, $U_{x}$, during the campaign: 2 tide. The points represent the data after a filtering process; the continuous lines are the raw data.

The cross-shore velocity component was well synchronized with the measured surface elevation, as shown in Figure 8. The maximum cross-shore flow velocity ranges between 0.5 and $2 \mathrm{~m} / \mathrm{s}$ for the whole record, with maximum onshore and offshore velocities occurring, approximately, at the beginning of the uprush and the end of the backwash, respectively. Flow reversal occurs just slightly after the time of maximum swash elevation.

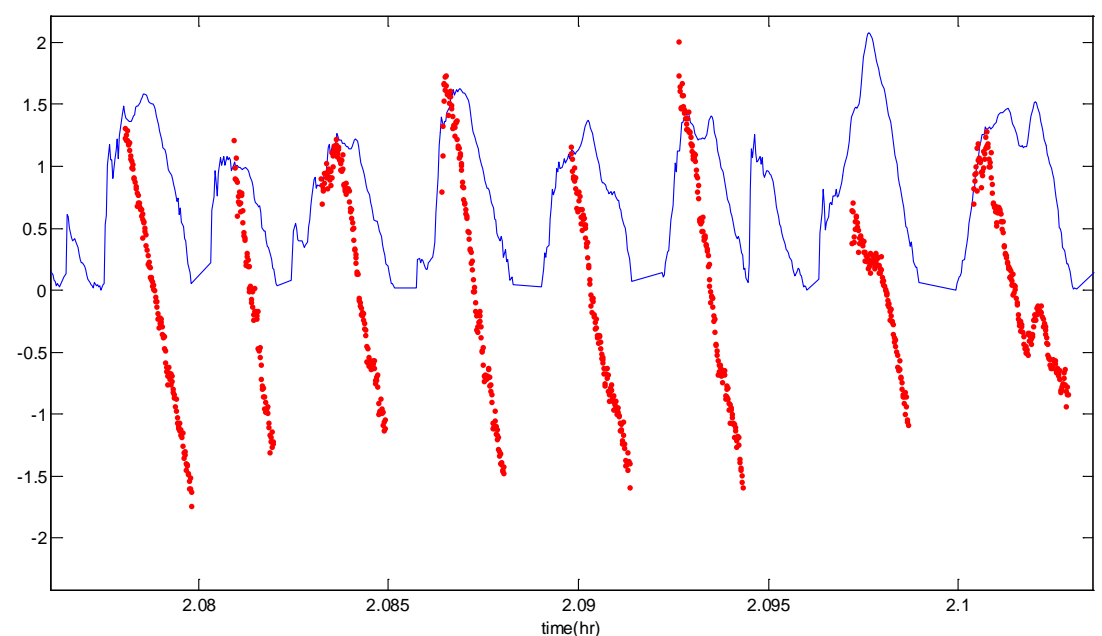

Figure 8. Example time series of PT3 measured surface elevation ( ${ }^{5}$ in meters) (continuous line) and flow cross-shore velocity, $U_{x}(\mathrm{~m} / \mathrm{s}),($ dots $): 2^{\text {nd }}$ tide.

A statistical analysis of different quantities was made considering 10-minute intervals, as before. Figure 9 presents the number of swash events identified, their time duration, the mean velocities during the uprush (positive) and downwash (negative) phases, the velocity skewness $\left(\mathrm{U}_{\mathrm{sk}}\right)$ and kurtosis $\left(\mathrm{U}_{\mathrm{ku}}\right)$ and a parameter $\alpha$ that quantifies the orbital velocity asymmetry (Suntoyo et al., 2008):

$$
\begin{aligned}
& U_{s k}= \frac{\left\langle U_{x}{ }^{3}>\right.}{\left.<U_{x}{ }^{2}\right\rangle^{1.5}} \\
& U_{k u}= \frac{\left\langle U_{x}{ }^{4}>\right.}{\left.<U_{x}{ }^{2}\right\rangle^{2}} \\
& \alpha=\frac{2 T_{p c}}{T}
\end{aligned}
$$



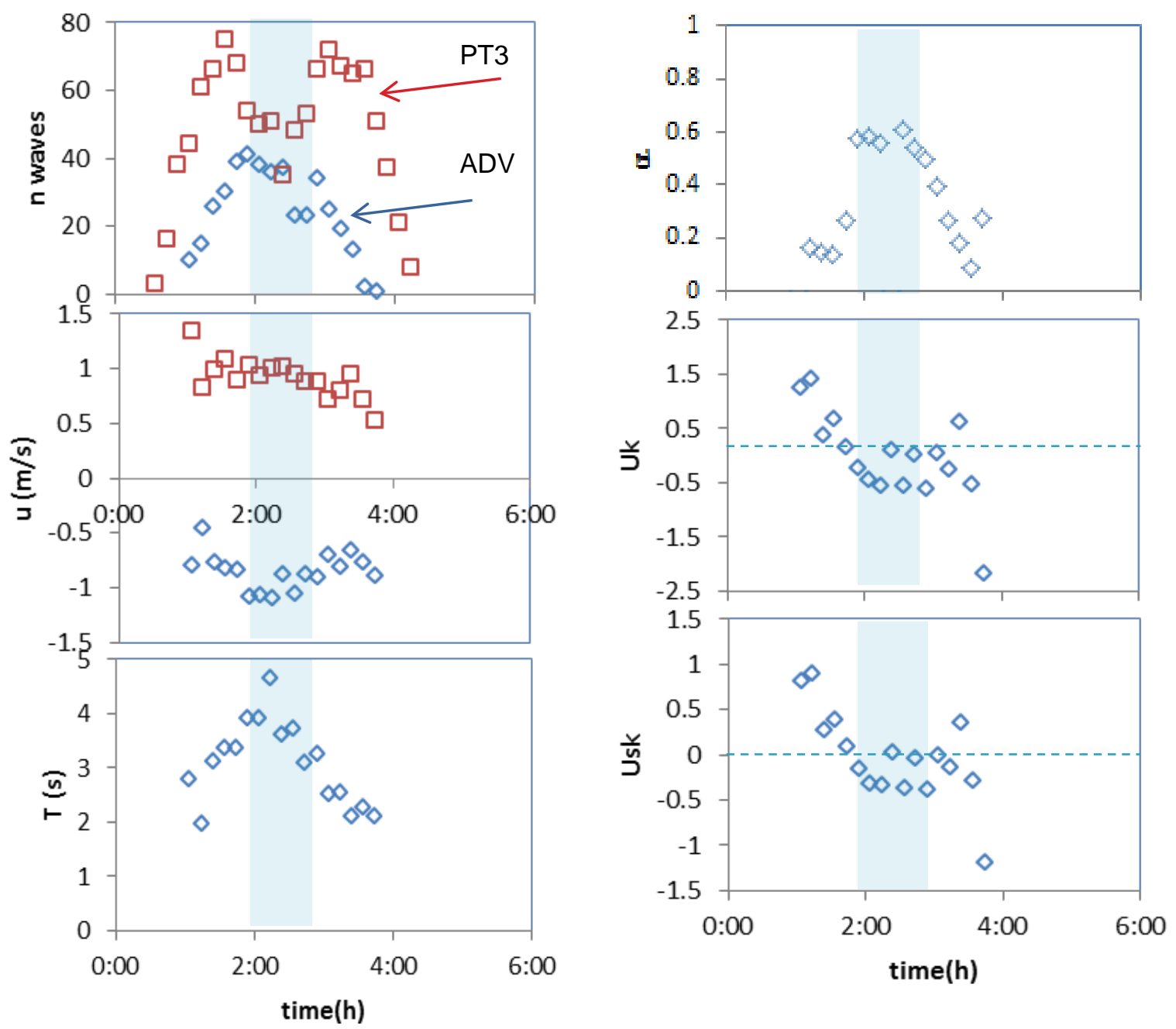

Figure 9. ADV data: number of waves, average onshore and offshore velocities, $T$, velocity skewness, kurtosis and parameter $\alpha$ at $\mathbf{1 0}$ min intervals: 2 tide

The angle brackets in equations (1-2) denote time average and $\mathrm{T}_{\mathrm{pc}}$ is the time between flow reversal and maximum onshore velocity. In order to estimate $T_{p c}$ from data, the time between the maximum onshore flow velocity and flow reversal $\left(U_{x}=0\right)$ for each swash event was computed and then subtracted to the time between the beginning of the swash event and the time of maximum swash height, as recorded by the PT3. In the transition zone, when one swash "event” is composed by several waves, this estimation is obviously not correct.

The analysis of Figure 9 shows that, as the mean water depth is increasing, the magnitude of the mean uprush and downwash velocities increases, the velocity skewness and kurtosis decrease and $\alpha$ tends to increase. This indicates that, as the waves propagate from the surf into the swash zone, the orbital velocities tend to be more asymmetric and positively skewed, i.e., with a steep wave front and higher uprush velocities than downwash velocities.

\section{SEDIMENT TRANSPORT ESTIMATIONS}

The two well-known sediment transport formulations of Bailard (1981) and Meyer-Peter and Müller (1948) were applied to compute the transport rates in the swash zone.

The net cross-shore sediment transport rate according to Bailard formula is given by: 


$$
\begin{aligned}
q=q_{b+} q_{s} & =\rho C_{f} \frac{\varepsilon_{b}}{\tan (\varphi)}\left[<\left(U_{x}{ }^{2}+U_{y}{ }^{2}\right) U_{x}>-\frac{\tan (\beta)}{\tan (\varphi)}<\left(U_{x}{ }^{2}+U_{y}{ }^{2}\right)^{3 / 2}>\right]+ \\
& +\rho C_{f} \frac{\varepsilon_{s}}{w_{s}}\left[<\left(U_{x}{ }^{2}+U_{y}{ }^{2}\right)^{3 / 2} U_{x}>-\frac{\varepsilon_{s} \tan (\beta)}{w_{s}}<\left(U_{x}{ }^{2}+U_{y}{ }^{2}\right)^{5 / 2}>\right]^{\prime},
\end{aligned}
$$

where $\mathrm{q}$ is the immersed-weight sediment transport rate, the subscripts ' $\mathrm{b}$ ' and ' $\mathrm{s}$ ' indicate, respectively, bed load and suspended load, $\rho$ is the seawater density of $\left(1024 \mathrm{~kg} \mathrm{~m}^{-3}\right), \mathrm{C}_{\mathrm{f}}$ is the friction coefficient, $\mathrm{w}_{\mathrm{s}}$ is the sediment fall velocity, $\varepsilon_{\mathrm{b}}$ and $\varepsilon_{\mathrm{s}}$ represent efficiency factors for the bed and suspended loads, $\tan (\phi)$ is the tangent of the internal angle of friction $(\tan (\phi)=0.63)$ and $\tan (\beta)$ is the local bed slope. The value of $\mathrm{w}_{\mathrm{s}}=0.086 \mathrm{~m} / \mathrm{s}$ was computed from the sand samples collected at the $\mathrm{ADV}$ site, and $\mathrm{d} 50=0.68 \mathrm{~mm}$. The values of the constants $\varepsilon_{\mathrm{b}}$ and $\varepsilon_{\mathrm{s}}$ are 0.135 and 0.015 , respectively, were defined according to Masselink et al. (2008), and were also already used by Emmanuel et al. (2009). Finally, the value of $\tan (\beta)$ is 0.1 , according to the topographic data at the ADV site.

The Meyer-Peter Müller type of formulation was also considered to compute the instantaneous dimensionless bed load sediment transport rate:

$$
\Phi=12\left[\theta(t)-\theta_{c r}\right] \theta(t)^{1 / 2}, \quad \theta>\theta_{c r}
$$

with $\theta_{c r}=0.05$. The Shields parameter, $\theta(\mathrm{t})$, was computed from:

$$
\theta(t)=\frac{u_{*}^{2}(t)}{(s-1) g d_{50}}, \quad u_{*}(t)=\sqrt{f_{w} / 2}(u)
$$

where $s=\rho_{s} / \rho$ is the ratio between sediment and water densities, $u_{*}(\mathrm{t})$ is the friction velocity and $f_{\mathrm{w}}$ is the friction coefficient, computed from Swart (1974) using a roughness equal to $2.5 d_{50}$. The volumetric transport rates were then computed from Equations (4-5) considering a constant porosity of 0.4.

Figure 10 presents the mean onshore, offshore and net transport rates for each 10-minute interval computed using Eq. (4), considering the standard values of $C_{f}=0.003$, and Eq. (5). The net transport rates are small $\left(-0.002 \mathrm{~m}^{3} / \mathrm{m}\right.$ and $-4 \times 10^{-4} \mathrm{~m}^{3} / \mathrm{m}$, respectively) and result, in both cases, from a difference of two large quantities. The magnitude of on- and off-shore directed transports increases as the water depth increases (from the surf zone to the swash zone); the net transport rates tend to be positive at the beginning and end of the tide, when the sensors are located in the swash zone; at higher water depths, in the transition zone, the net transport is negative. When the friction coefficients assume different values during the uprush $\left(\mathrm{C}_{\mathrm{f} \text { up }}=0.015\right)$ and backwash $\left(\mathrm{C}_{\mathrm{f} \text { down }}=0.009\right)$ phases (Barnes et al., 2009), the net transport rates become positive $\left(0.045 \mathrm{~m}^{3} / \mathrm{m}\right.$ ) (Figure 10c). The comparison of the computed net transport rates with those derived from the topographic data is inconclusive as the reported bed level changes are within the error of the topographic survey.

Consideration of flow acceleration/pressure gradients effects on the bed shear stress (friction velocity, in Eq. (6)) was proposed by Nielsen (1992; 2002), Terrile et al. (2009) and, recently, by Abreu et al. (2011). According to Abreu et al. (2011), the friction velocity can be modelled by:

$$
u_{*}(t)=\sqrt{\frac{f_{\mathrm{w}}}{2}}\left(\cos \left(\varphi_{\tau}\right) u(t)+\frac{\sin \left(\varphi_{\tau}\right)}{\omega}\left[\frac{\partial u(t)}{\partial t}-S(t, \phi, r)\right]\right)
$$

where $\mathrm{S}$ is given by:

$$
S(t, \phi, r)=\omega \cdot f \cdot U_{w} \frac{r[-(-1+f) \cos \phi-2 r \cos (\omega t)+(1+f) \cos (2 \omega t+\phi)]}{2(1+f)[-1+r \cos (\omega t)]^{2}}
$$



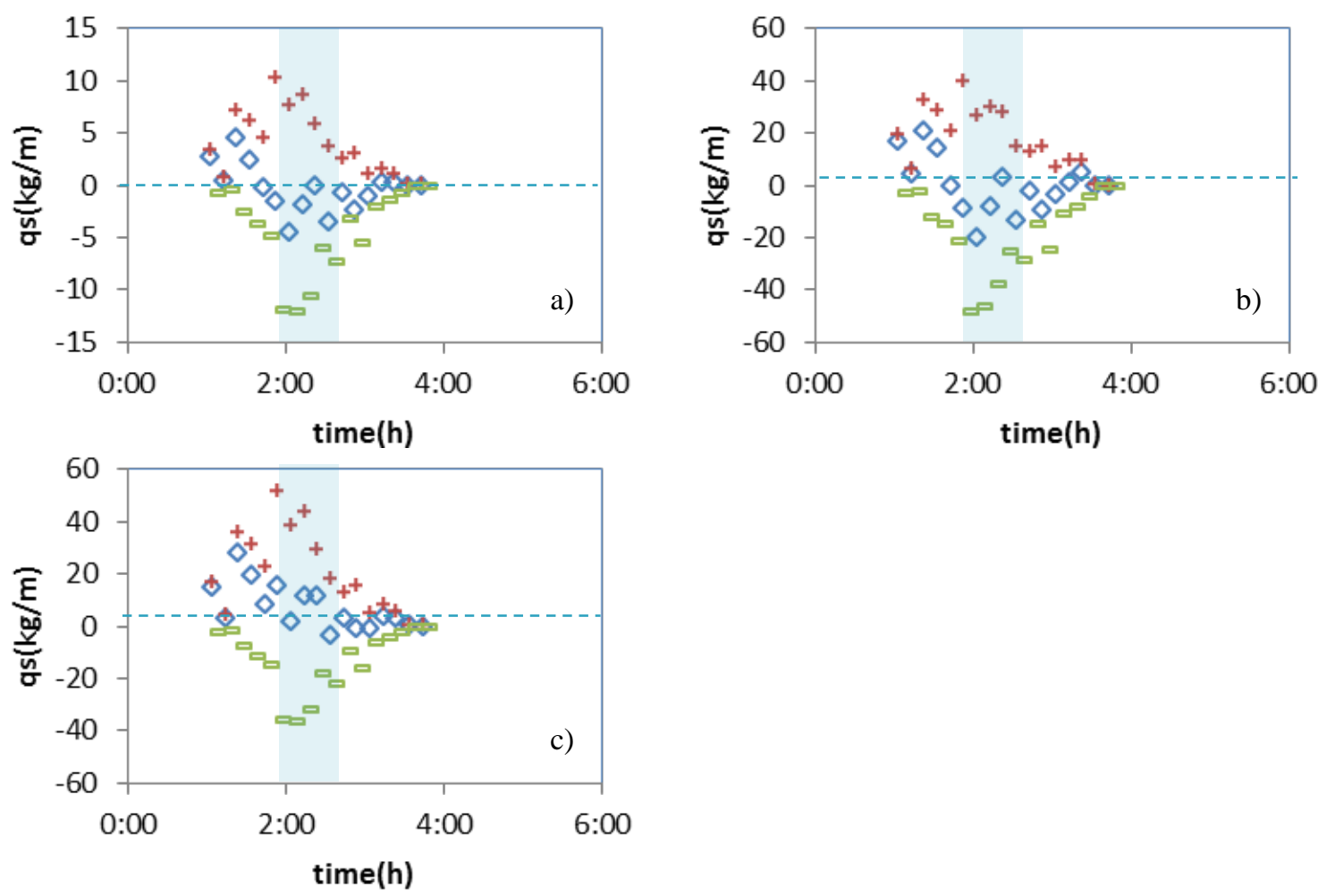

Figure 10. Computed onshore(+), offshore (-) and net transport rates ( $\diamond)$ (a) Bailard; (b) MPM; (c) Bailard different Cf: 2 tide

Equation (8) was deduced considering the formulation of the non-linear near-bed orbital velocity of Abreu et al. (2010):

$$
u(t)=U_{w} f \frac{\left[\sin (\omega t)+\frac{r \sin \phi}{1+\sqrt{1-r^{2}}}\right]}{[1-r \cos (\omega t+\phi)]} .
$$

In Equations (7-9), $\phi$ is a waveform parameter and $r$ reflects the index of skewness or nonlinearity $(-1<\mathrm{r}<1)$. Knowledge of the velocity amplitude, $\mathrm{U}_{\mathrm{w}}$, the velocity skewness, and asymmetry parameter $\alpha$ allow the calculation of a velocity time series for each 10-min interval, from which the bed shear stress can be computed. This allows the study of the effect of the changing wave non-linearity in the swash zone and its effect on the bed shear stress and sediment transport. Note that Malarkey and Davies (2012) found a good fit of the Abreu et al. (2010) formulation to phase-ensemble, swash freestream velocity experimental data.

Figure 11 shows the representative swash velocity time series for selected 10-minute intervals during the rising and falling tide (outside the transition zone), and the corresponding bed shear stress for $\varphi_{\mathrm{t}}=0^{\circ}$ and $\varphi_{\mathrm{t}}=51^{\circ}$, whereby the acceleration term is disregarded or considered, respectively, in Equation (7). The phase difference value $\varphi_{\mathrm{t}}=51^{\circ}$ was chosen according to Nielsen (2006).

The results show that the bed shear stress skewness decreases as the mean water depth at the ADV site increases and that the consideration of the acceleration terms in Equation (7) increases significantly both the bed shear stress magnitude and skewness. This justifies that the net transport rates computed from the MPM-type formulation decrease with increasing water depth, leading to the enhancement of the onshore transport when the acceleration terms are considered (Figure 12 present the corresponding net transport rates). Moreover, as shown in Figure 13, the net transport rates computed from the representative swash velocity time series, considering $\varphi=0^{\circ}$, agree reasonably well $\left(R^{2}=0.5\right)$ with those computed considering the individual swash events presented in Figure 10b. 

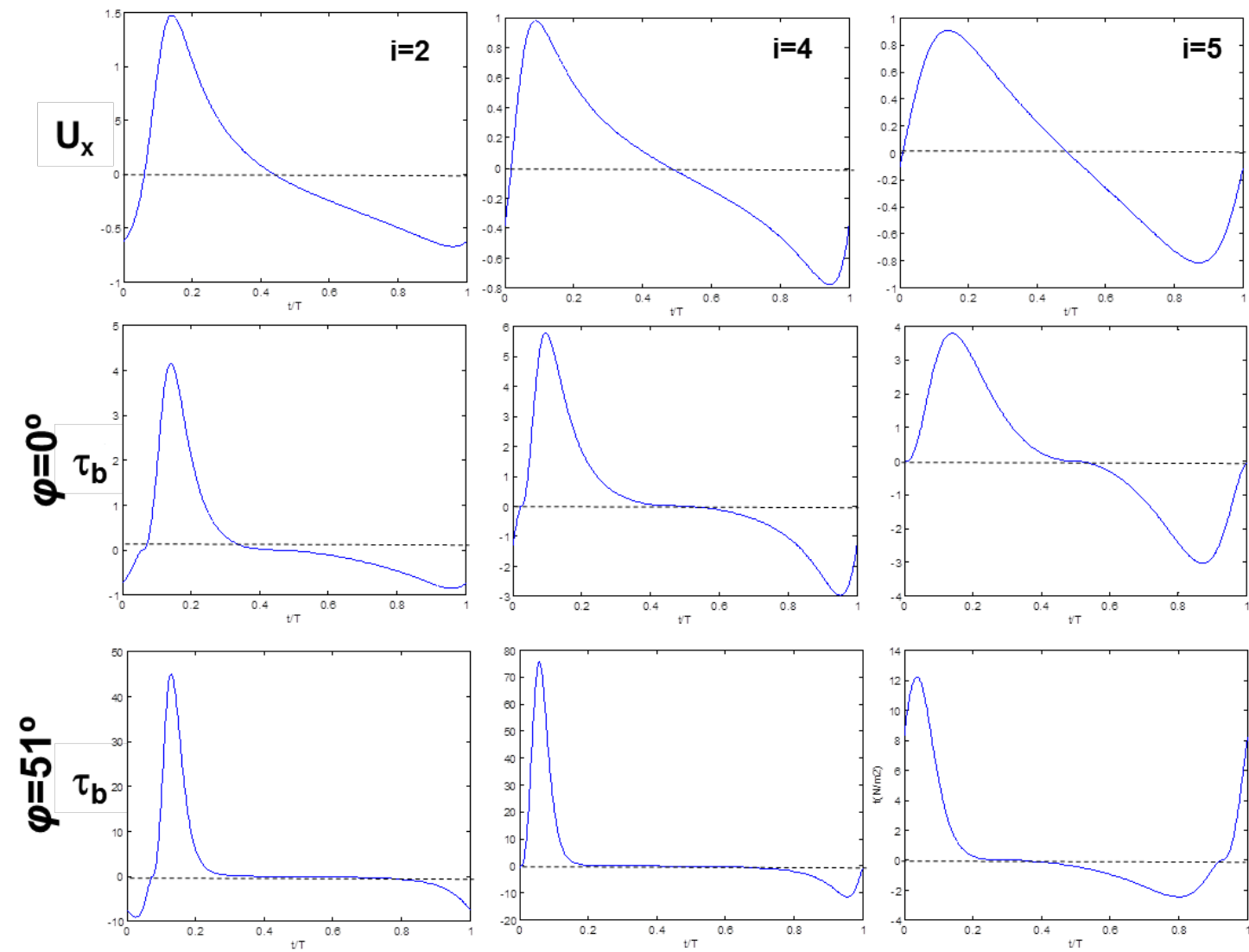

Figure 11. Representative velocity time-series (upper panel) and bed shear stress $\left(\mathrm{N} / \mathrm{m}^{2}\right)$ computed from Equation (7) with $\varphi_{t}=0$ (middle panel) and $\varphi_{t}=51^{\circ}$ (lower) at selected 10 min intervals.

\section{CONCLUSIONS}

The characteristics of the swash motion in Praia de Faro were established from collocated ADV and PT measurements during a tidal cycle. A considerable number of swash events were identified. The swash motion had the same frequency as incoming waves, which is characteristic of small waves in steep beaches. The cross-shore velocities correlate well with the surface elevation: the flow reversal occurred at times of high elevation and maximum velocities $(\sim 2 \mathrm{~m} / \mathrm{s})$ at the beginning and end of each swash event. The velocity skewness and asymmetry show a dependency on the tidal phase: as the water depth increases, the velocity skewness tends to be less positive and asymmetry decreases. The results are limited by the fact that the measurements were taken some $\mathrm{cm}$ above the bed.

Sediment transport estimated from Bailard and Meyer-Peter Müller formulations shows that uprush and backwash transports were higher near high tide, when a significant number of swash events were identified. There is probably an underestimation of the uprush and backwash sediment transport, because the velocity record did not capture the beginning and end of the swash. Net transport rates during the tidal cycle are very small and comparable to those computed from the topography measurements. However, since the bed level changes recorded during the tidal cycle are within the error of the DGPS, the analysis of which formulation provides the best result is inconclusive. Besides that, both formulations predict onshore net transport rates in the swash zone, and offshore in the transition zone.

A representative swash velocity time series was built from average values of skewness and asymmetry using Abreu et al. (2010) formulation. The computed bed shear stress skewness depends on the tidal phase, being higher for lower water depths. This determines the direction and magnitude of the net transport rate in the swash zone. When wave asymmetry is considered, either by including the acceleration terms in the bed shear stress estimator or by considering different values for the uprush and backwash friction coefficients, both formulations give rise to higher onshore net transport rates. 

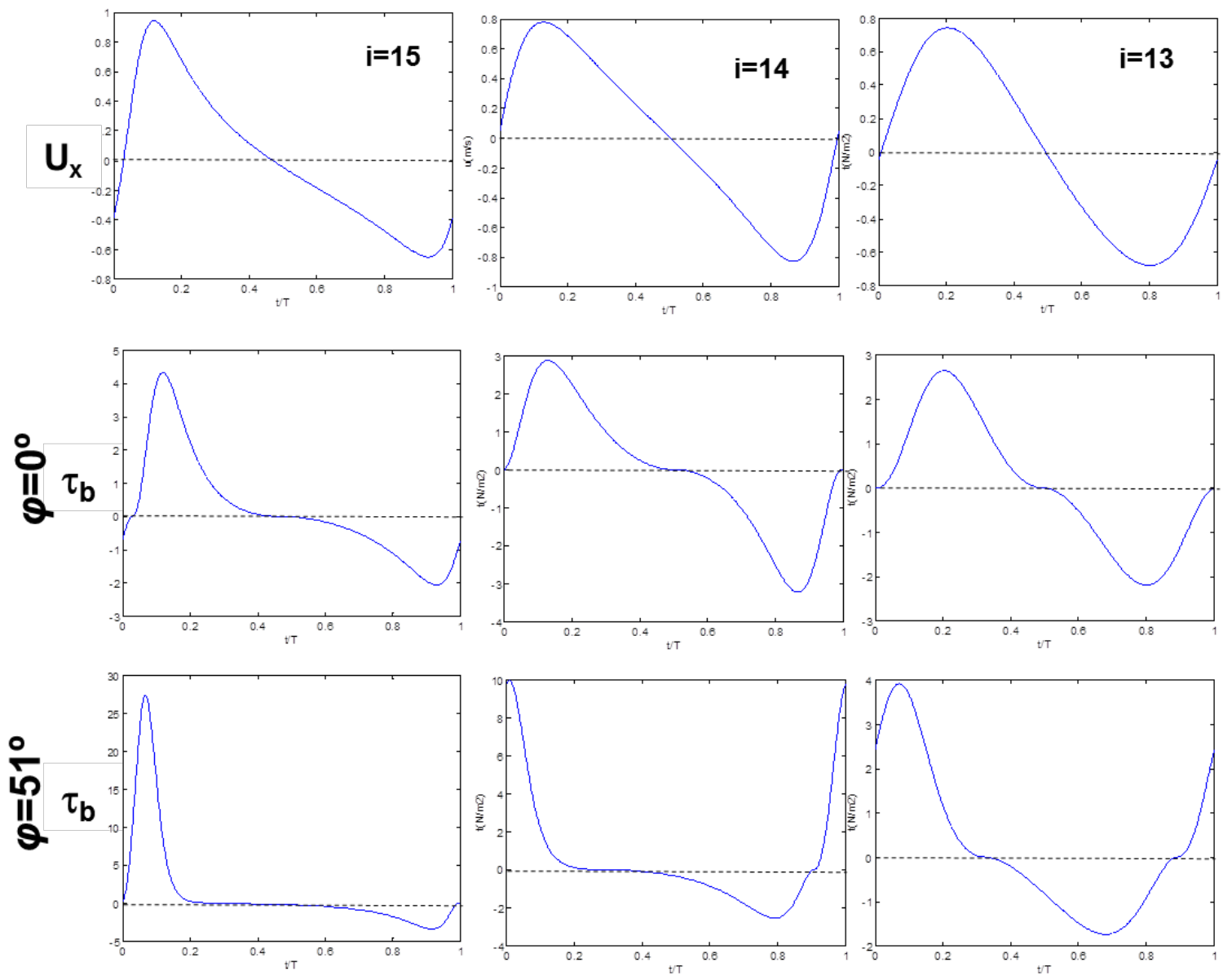

Figure 11. (cont.)
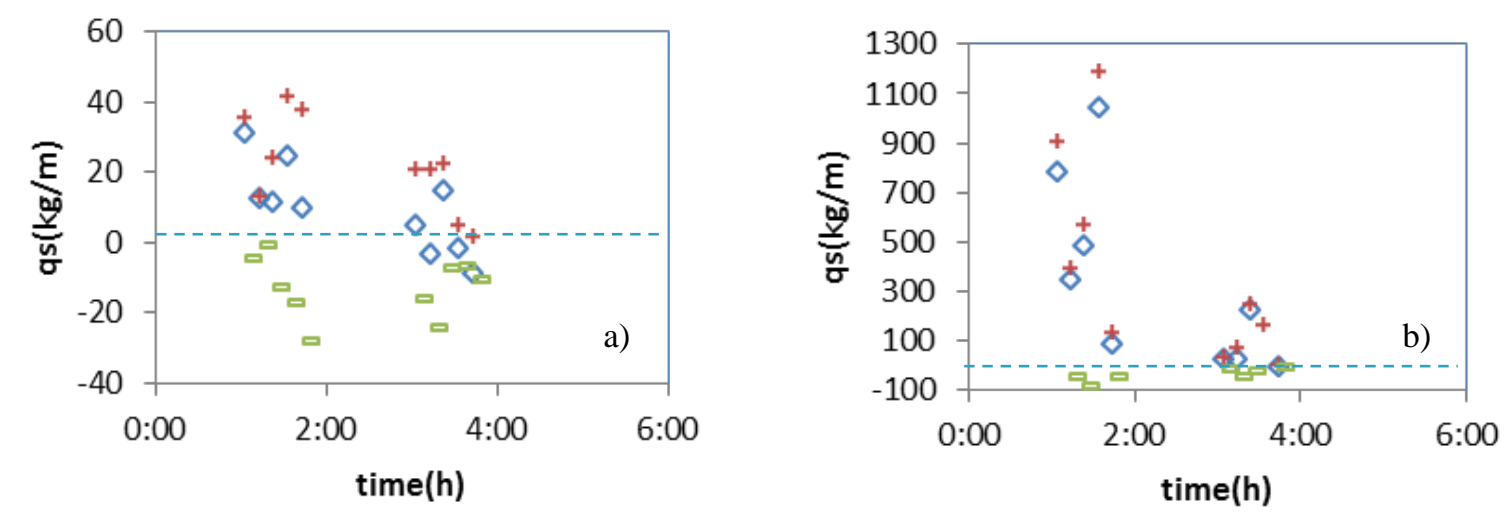

Figure 12. Computed onshore(+), offshore (-) and net transport rates $(0)$ with MPM and Equation (7) for the representative velocity time series (a) $\varphi_{t}=0$ and (b) $\varphi_{t}=51^{\circ}$. Computations for the cases in the transition zone were not made. 


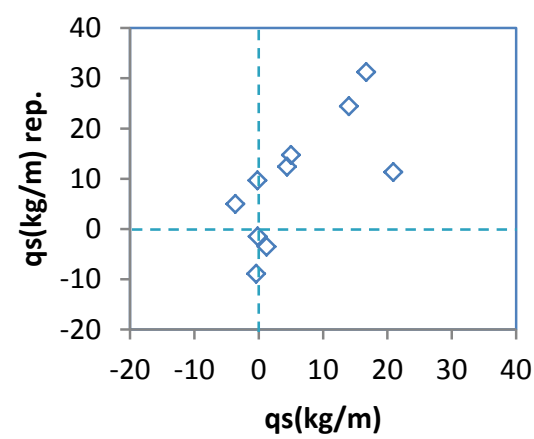

Figure 13. Computed net transport rate with MPM: computation made based on the swash events vs. the representative velocity time series.

\section{ACKNOWLEDGMENTS}

This work has been supported by FCT and by European Union (COMPETE, QREN, FEDER) in the frame of the research projects: BRISA (PTDC/ECM/67411/2006) and EROS (PTDC/CTEGIX/111230/2009).

\section{REFERENCES}

Abreu, T., Silva, P.A., Sancho, F. and Temperville, A. 2010. Analytical approximate wave form for asymmetric waves. Coastal Engineering, 57(7), 656-667.

Abreu, T., van der A, D.A., Silva, P.A., Sancho, F. and Michallet, H. 2011. New bed shear stress estimator for net sand transport rate predictions under non-linear waves. Journal of Coastal Research, SI 64, 2007-2011.

Austin, M., Masselink G., O'Hare T. and Russell P. 2009. Onshore sediment transport on a study beach under varied wave conditions: Flow velocity skewness,wave asymmetry or bed ventilation?. Marine Geology, Vol. 259: 86-101.

Bailard, J.A., 1981. An energetics total load sediment transport model for a plane sloping beach. Journal of Geophysical Research, 86(C11), 10938-10954.

Bakhtyara, R., Barry, D.A., Li, L., Jeng, D.S. and A. Yeganeh-Bakhtiary, 2009. Modeling sediment transport in the swash zone: A review, Ocean Engineering, vol. 36, 767-783.

Barnes, M.P., O'Donoghue, T., Alsina, J.M. and Baldock, T.E. 2009. Direct bed shear stress measurements in bore-driven swash. Coastal Engineering, Vol. 56, 853-867.

Costa, M., R. Silva, and J. Vitorino. 2001. Contribuição para o Estudo do Clima de Agitação Marítima na Costa Portuguesa. Actas das 2as Jornadas Portuguesas de Engenharia Costeira e Portuária. Associação Internacional de Navegação, Sines, Portugal.

Cox, D. T., W. A. Hobensack, and A. Sukumaran, 2000. Bottom stress in the inner surf and swash zone. Proceedings of 27th International Conference on Coastal Engineering, Vol. ASCE: 108119.

Conley, D.C. and J. G. Griffin Jr., 2004. Direct measurements of bed stress under swash in the field. $J$. Geophys. Res. Vol. 109, C03050.

Emmanuel, I. J.P. Parisot, H. Michallet, E. Barthélemy and N. Sénéchal. 2009. Sediment transport particular events and beach profile response. Journal of Coastal Research, SI 56, 1766-1770.

Fortes C.J., Ferreira Ó., Silva P.A., Moura T., Capitão R., Amante L., Vousdoukas M., Bezerra M. (2012) Joint use of data and modeling in coastal wave transformation. Journal of Coastal Conservation. //dx.doi.org/10.1007/s11852-012-0187-2

Hsu, T.-J., Raubenheimer, B. 2006. A numerical and field study on inner-surf and swash sediment transport, Cont. Shelf Res., 26, 589-598

Instituto Hidrográfico (1998) Tabela de Marés, volume 1. Lisboa, ed. Instituto Hidrográfico, 178 pp (in Portuguese)

Malarkey, J., and A.G. Davies, 2012. Free-stream velocity descriptions under waves with skewness and asymmetry. Coastal Engineering, 68, 78-95.

Masselink, G. and Hughes, M., 1998. Field investigation of sediment transport in the swash zone, Continental Shelf Research, Vol. 18, 1179-1199. 
Masselink, G., Evans, D., Hughes, M. G., and Russel, P., 2005. Suspended sediment transport in the swash zone of a dissipative beach, Marine Geology, Vol. 216, 169-189.

Masselink, G. and Russel P., 2006. Flow velocities, sediment transport and morphological change in the swash zone of two contrasting beaches. Marine Geology, Vol. 227, 227-240.

Masselink, G., Austin, M. Tinker, J. O'Hare, T. and Russell, P., 2008. Cross-shore sediment transport and morphological response on a microtidal beach with intertidal bar morphology, Truc Vert, France. Marine Geology, Vol. 251, 141-155.

Matias A, Vila-Concejo A, Ferreira Ó, Morris B, Dias JA (2009) Sediment dynamics of barriers with frequent overwash. $J$ Coast Res 25(3), 768-780

Meyer-Peter, E. and Müller, R., 1948. Formulas for bed-load transport, IAHR, 2nd Meeting of the International Association for Hydraulic Structures Research, Stockholm, Sweden, 39-64.

Nielsen, P., 1992. Coastal bottom boundary layers and sediment transport. World Scientific, 324 pp.

Nielsen, P., 2002. Shear stress and sediment transport calculations for swash zone modelling. Coastal Engineering, 45(1), 53-60.

Nielsen, P., 2006. Sheet flow sediment transport under waves with acceleration skewness and boundary layer streaming. Coastal Engineering, 53(9), 749-758.

Nielsen, P., 2009. Coastal and Estuarine Processes. Advanced Series on Ocean Engineering, 29. World Scientific, 360 pp.

Puleo, J.A., Lanckriet, T. and P. Wang, 2012. Near bed cross-shore velocity profiles, bed shear stress and friction on the foreshore of a microtidal beach, Coastal Engineering, 68, 6-16.

Suntoyo, Tanaka, H. and Sana, A., 2008. Characteristics of turbulent boundary layers over a rough bed under saw-tooth waves and its application to sediment transport. Coastal Engineering, 55(12), 1102-1112.

Swart, D.H., 1974. Offshore sediment transport and equilibrium beach profiles. Publication / Delft Hydraulics Laboratory, Delft, The Netherlands, 302 pp.

Terrile, E., Reniers, A.J.H.M., Stive, M.J.F., 2009. Acceleration and skewness effects on the instantaneous bed-shear stresses in shoaling waves. Journal of Waterway, Port, Coastal, and Ocean Engineering 135, 228, ASCE. doi: 10.1061/(ASCE)0733-950X(2009)135:5(228).

Vousdoukas, M. and L.P. Almeida, 2009. Internal Ciacomar Report 06/09: MICORE-Intensive Campaign Report, 52 pp. 